febrile seizure, their prevalence, and the risk of seizure recurrence.

of all respondents, only $13 \%$ were not afraid of fever, and $45 \%$ were afraid or very afraid. Parents of non-West European background were more afraid, and considered a temperature of $39.0^{\circ} \mathrm{C}$ as high fever. Child care measures taken by parents who were more afraid included more frequent temperature recordings (30\% measured the temperature 5-8 times in 24 hours vs $14 \%$ for those less afraid), sleeping in the same room (36\% vs $15 \%)$, and remaining awake at night (22\% vs $5 \%$ ). Only $5 \%$ had diazepam ready for use. Questioned about their thoughts at the moment of their child's initial febrile seizure, $47 \%$ of parents thought the child was dying; only $8 \%$ were worried about epilepsy. When asked about their current thoughts of febrile seizures, $54 \%$ answered that they were harmful, mainly because they looked damaging. Of $44 \%$ of parents who considered febrile seizures not harmful, one half had been convinced by reassuring information received, mainly at the hospital outpatient clinic. Fear of a recurrence of febrile seizures in $44 \%$ of parents was significantly associated with fear of fever. (van Stuijvenberg M, de Vos S, Tjiang GCH et al. Parents' fear regarding fever and febrile seizures. Acta Paediatr June 1999;88:618-622). (Respond: Dr HA Moll, Sophia Children's Hospital, Department of Paediatrics, Room Sp 1543, Dr Molewaterplein 60, 3015 GJ Rotterdam, The Netherlands).

COMMENT. Parents' fear of a child's impending death, alluded to in a 1968 monograph on Febrile Convulsions (Millichap JG, Macmillan), has apparently not changed in 30 years, despite the physicians' reassurance and generally sanguine prognosis. Parental fear of fever and febrile seizures is a common occurrence, affecting almost $50 \%$ of families involved. Fever is feared because of its association with recurrence of a seizure. Those who are less afraid of fever and seizures attribute their reassurance to information received in a hospital clinic and not from the practitioner or child health center.

Comparing these results with a previous study involving the reaction of inexperienced parents to a child's first febrile seizure, the frequency of fear of febrile seizures is similar (Balslev T. Acta Paediatr Scand 1991;80:466-469). Fear that the child would die during the seizure was volunteered by $44 \%$, and another $33 \%$ admitted the same concern when specifically asked about it. General knowledge of febrile seizures was low, and many parents wished they had received more information about fever and the risks of febrile seizures. See Progress in Pediatric Neurology II, PNB Publ, 1994;pp19-20.

Few studies address the benefits and potential lessened anxiety of parents instructed in the use of rectal diazepam gel for the prevention and treatment of recurrent febrile seizures. (Kriel RL et al. Pediatr Neurol 1999;20:282-288). See Ped Neur Briefs June 1999;13:46, for commentary on the efficacy and safety of Diastat in treatment of acute repetitive seizures.

The importance of parental education in the management of fever and febrile seizures is emphasized by these reports, and especially in families with a history of febrile seizures or epilepsy. Parental anxiety may be allayed by the prescription of intermittent diazepam given at times of fever, although poor compliance may lessen its effectiveness in practice.

\title{
CHROMATIC SENSITIVE EPILEPSY
}

A study of 4 boys with cartoon-evoked epileptic seizures, conducted at Kyushu University, Fukuoka, Japan, was prompted by a report of 685 Japanese children and some adults who suffered generalized convulsions while watching an animated TV program called "Pocket Monsters." One of the 4 affected boys had previous febrile convulsions, none had afebrile seizures, and 2 had a family 
history of epilepsy. Brain imaging studies were normal. Two showed paroxysmal EEG abnormalities with intermittent photic stimulation. All 4 with cartoon-evoked seizures had a $3-\mathrm{Hz}$ spike-and-wave photoparoxysmal response (PPR) when exposed to the blue/red colored cartoon frames at 6 and $12 \mathrm{~Hz}$ flicker rates, and less frequently, only at $12 \mathrm{~Hz}$ flicker, with a monochromatic gray/black version of the cartoon. In contrast, 2 boys with TV game epilepsy were unaffected by the cartoon. (Tobimatsu S, Zhang YM, Tomoda Y, Mitsudome A, Kato M. Chromatic sensitive epilepsy: a variant of photosensitive epilepsy. Ann Neurol June 1999;45:790-793). (Respond: Dr Tobimatsu, Department of Clinical Neurophysiology, Neurological Institute, Faculty of Medicine, Kyushu University, 3-1-1 Maidashi, Higashi-Ku, Fukoka 812-8582, Japan).

COMMENT. TV producers of children's programs need to be alerted not only to the adverse effects of violence but also to the color content of their cartoons. Factors responsible for precipitating photosensitive epileptic seizures include light, pattern, stimulus frequency, and, in addition, the blue/red colors. Testing for chromatic sensitivity should be added to the list of activating procedures during EEG recordings in children with suspected photosensitive epilepsy.

\section{TOPIRAMATE IN LENNOX-GASTAUT SYNDROME}

The efficacy and safety of topiramate as adjunctive therapy for LennoxGastaut syndrome were studied in an 11-week multicenter, double-blind, placebocontrolled trial involving 98 patients, 1-30 years of age, and reported from the New Jersey-Robert Wood Johnson Medical School, New Brunswick, NJ. A greater than $50 \%$ reduction in drop attacks and tonic-clonic seizures was obtained in one third, and parental global evaluations indicated a reduction in seizure severity. Adverse events occurring with greater frequency in the topiramate patients than in controls included somnolence, anorexia, nervousness, behavioral problems, fatigue, dizziness, and weight loss, but none caused treatment to be completely withdrawn. (Sachdeo RC, Glauser TA, Ritter F et al, and Topiramate YL Study Group. A double-blind, randomized trial of topiramate in Lennox-Gastaut syndrome. Neurology June 1999;52:1882-1887). (Reprints: Dr Rajesh C Sachdeo, University of Medicine and Dentistry of New Jersey-Robert Wood Johnson Medical School, 97 Paterson St, Room 118, New Brunswick, NJ 08903).

COMMENT. Topiramate may be effective as adjunctive therapy in LennoxGastaut syndome.

Topiramate pharmacokinetics and tolerability were studied in 18 children, 4-17 years of age, at the Epilepsy Care Center, Chesterfield, MO, using graded doses from $1 \mathrm{mg} / \mathrm{kg} /$ day, increasing weekly to $9 \mathrm{mg} / \mathrm{kg} /$ day or $800 \mathrm{mg} /$ day at the 4th week. (Rosenfeld WE et al. Pediatr Neurol May 1999;20:339-344). Oral plasma clearance was independent of dose, and plasma concentrations were proportional to the dose. Topiramate clearance was $50 \%$ greater than that in adults, and higher in children receiving enzyme-inducing antiepileptic drugs. Steady-state plasma topiramate concentrations are $33 \%$ lower in pediatric than in adult patients, for the same $\mathrm{mg} / \mathrm{kg}$ dose. Adverse events occurring in $39 \%$ to $17 \%$ of patients included anorexia, fatigue, nervousness, and attention problems.

\section{RISK OF STEVENS-JOHNSON SYNDROME WITH AED THERAPY}

The role of antiepileptic drugs in Stevens-Johnson syndrome (SJS) and toxic epidermal necrolysis (TEN) was evaluated in a case-control study in Europe and reported from Mannheim, Germany. Of 352 cases of SJS/TEN, 73 (21\%) had received antiepileptic drugs, and of the cases associated with AEDs, 8 (11\%) died. 